\title{
Assessment of the consistency among global microwave land surface emissivity products
}

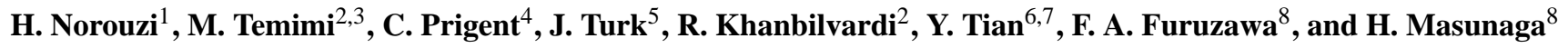 \\ ${ }^{1}$ Department of Construction Management and Civil Engineering Technology, New York City College of Technology, \\ Brooklyn, New York, USA \\ ${ }^{2}$ Civil Engineering Department, NOAA-CREST, the City College of New York, New York, New York, USA \\ ${ }^{3}$ Masdar Institute of Science and Technology, Institute Center for Water and Environment (iWater), Abu Dhabi, \\ United Arab Emirates \\ ${ }^{4}$ Laboratoire d'Etudes du Rayonnement et de la Matière en Astrophysique et Atmosphères, Centre National de la Recherché \\ Scientifique, Paris, France \\ ${ }^{5}$ Jet Propulsion Laboratory, Pasadena, California, USA \\ ${ }^{6}$ Univ. Maryland College Park, College Park, Maryland, USA \\ ${ }^{7}$ NASA's Goddard Space Flight Center, Greenbelt, Maryland, USA \\ ${ }^{8}$ Hydrospheric Atmospheric Research Center, Nagoya University, Nagoya, Japan
}

Correspondence to: H. Norouzi (hnorouzi@ citytech.cuny.edu)

Received: 26 August 2014 - Published in Atmos. Meas. Tech. Discuss.: 26 September 2014

Revised: 2 February 2015 - Accepted: 17 February 2015 - Published: 11 March 2015

\begin{abstract}
The goal of this work is to intercompare four global land surface emissivity products over various landcover conditions to assess their consistency. The intercompared land emissivity products were generated over a 5year period (2003-2007) using observations from the Advanced Microwave Scanning Radiometer - Earth Observing System (AMSR-E), the Special Sensor Microwave Imager (SSM/I), the Tropical Rainfall Measuring Mission (TRMM) Microwave Imager (TMI), and WindSat. First, all products were reprocessed in the same projection and spatial resolution as they were generated from sensors with various configurations. Then, the mean value and standard deviations of monthly emissivity values were calculated for each product to assess the spatial distribution of the consistencies/inconsistencies among the products across the globe. The emissivity products were also compared to soil moisture estimates and a satellite-based vegetation index to assess their sensitivities to changes in land surface conditions.

Results show the existence of systematic differences among the products. Also, it was noticed that emissivity values in each product have similar frequency dependency over different land-cover types. Monthly means of emissivity values from AMSR-E in the vertical and horizontal polariza-
\end{abstract}

tions seem to be systematically lower than the rest of the products across various land-cover conditions which may be attributed to the 01:30/13:30 LT overpass time of the sensor and possibly a residual skin temperature effect in the product. The standard deviation of the analyzed products was lowest (less than 0.01 ) in rain forest regions for all products and highest at northern latitudes, above 0.04 for AMSR-E and SSM/I and around 0.03 for WindSat. Despite differences in absolute emissivity estimates, all products were similarly sensitive to changes in soil moisture and vegetation. The correlation between the emissivity polarization differences and normalized difference vegetation index (NDVI) values showed similar spatial distribution across the products, with values close to the unit except over densely vegetated and desert areas.

\section{Introduction}

In numerical weather prediction (NWP) models, instantaneous microwave land surface emissivity is an important boundary condition that needs to be determined accurately in order to retrieve reliable atmospheric profiles. It was sug- 
gested that a $1 \%$ accuracy level in emissivity retrievals is required in applications such as NWP and microwave satellitebased precipitation algorithms (Karbou et al., 2006) to ensure the development of reliable weather products. Other applications of emissivity values include determination of changes in land surface condition as well as understanding the variability of land emissivity, which implies relying on estimates from different sensors and therefore the importance of investigating the consistency among the available products.

A number of microwave land emissivity products that are associated with different sensors have been proposed in the literature. The sensors used to infer land emissivity have common and, in certain cases, unique frequency channels. Relying on a single sensor's estimates reduces the potential of the available retrievals from the other sensors. It is therefore important to integrate all retrievals to maximize the spectral range of land emissivity products for an effective use, among others, in land surface classification. However, this requires understanding the consistency among the existing products, which is the first necessary step towards integrating land surface emissivity values from different sensors.

The sources of discrepancies among the existing land emissivity products are various, and they mainly fall into one of the two following categories. The first category includes the sensor's parameters. As microwave land surface emissivity values are impacted by several surface and subsurface parameters - like soil moisture, vegetation structure and density, freeze and thaw states, soil texture, and topography - a change in one or a number of these land parameters should impact the determined land emissivity differently depending on the configuration of the sensor, e.g., frequency, polarization, overpass time, incident angle, and footprint. In addition, even if two sensors concur in terms of frequency and observation geometry, a difference in their calibration process may introduce a gap between their readings. Polar orbiting satellites, which observe the earth at least twice a day, have different acquisition times that make their corresponding brightness temperature vary.

The second category of factors which may affect the consistency among the land emissivity products is relative to the retrieval method and the ancillary data used, which may introduce an inherent difference in the emissivity estimates. Physical models and retrieval techniques have commonly been utilized to estimate land surface emissivity with their own benefits and pitfalls. The retrieval of land emissivity involves the use of land surface temperature, which could be obtained from another sensor, like the Moderateresolution Imaging Spectroradiometer (MODIS) or from reanalysis like the National Centers for Environmental Prediction (NCEP) outputs. Theoretically, in emissivity retrievals the effect of temperature is removed and one should expect similar surface conditions from different sensors regardless of their acquisition time, especially when they are aggregated on a monthly scale. Emissivity is calculated using a radiative transfer model traditionally for cloud-free scenes since clouds greatly affect the signal. However, even over cloud-free pixels, accounting for the atmospheric contribution was necessary, especially for frequencies higher than $19 \mathrm{GHz}$. Many studies have attempted to estimate emissivity using forward modeling (Ringerud et al., 2014; Boukabara et al., 2011; Weng et al., 2001). These models often use emissivity retrieval from satellite observations as a reference in their algorithms. Physical radiative transfer models benefit from including all controlling parameters in algorithms. However, such a comprehensive approach requires several inputs, such as soil type, moisture, and temperature, which are difficult to obtain on large or global scales (e.g., Weng et al., 2001; Ringerud et al., 2014). Global land emissivity retrieval first was developed by Prigent et al. (1998) when brightness temperatures from the Special Sensor Microwave Imager (SSM/I) were used. Other available products later were proposed from other sensors, such as the Advanced Microwave Scanning Radiometer - Earth Observing System (AMSR-E) (Norouzi et al., 2011; Moncet et al., 2011), the Advanced Microwave Sounding Unit (AMSU) (Karbou et al., 2005), and the Tropical Rainfall Measuring Mission (TRMM) Microwave Imager (TMI) (Furuzawa et al., 2012). To retrieve land emissivity values, those studies did not necessarily use the same ancillary data, radiative transfer model, and assumptions to account for the atmospheric contribution. Also, microwave brightness temperatures from a variety of sensors with varying configurations (e.g., observation geometry, frequency, resolution) were used to generate the global land emissivity maps. Therefore, discrepancies among the available land global emissivity maps are expected.

Emissivity estimates from different products were first intercompared as part of a joint effort by members of the Land Surface Working Group (LSWG) of the Global Precipitation Measurement (GPM) mission, with the goal of improving retrievals from the recently launched GPM satellite (Ferraro et al., 2013). The emissivity estimates were compared at three points that coincide with previous and ongoing in situ measurements for Soil Moisture Active Passive (SMAP) and GPM missions. The results showed noticeable differences among estimates, with similar seasonal trends and variability.

In another study (Tian et al., 2014), the emissivity estimates from various sensors and providers at four locations with different land-cover types: two desert and two rain forest locations were evaluated, and large discrepancies were found across the sensors with different spectral signatures. The study of Tian et al. (2014) accounted for random and systematic errors using statistical approaches and suggested that the differences among retrievals are caused likely by cloud or rain contaminations.

The goal of this study is to expand the point-based intercomparisons to a global scale and to investigate the relative consistency among different land surface emissivity products. The lack of ground truth measurements on a global scale made the validation and the benchmarking of each 
land emissivity product difficult. In this study, we propose to overcome this lack of ground truth data by investigating the consistency among the available global land emissivity estimates from different sensors. The focus is on emissivity retrievals from microwave sensors with a constant incidence angle over a 5-year period. We assume that the consistency among the existent land emissivity products is an indicator of the reliability of the retrievals. The analysis of the consistency among the products was conducted over different land classes. It quantitatively compares available estimates from different sensors. It is, to our knowledge, the first attempt to assess the consistency among land emissivity products over different land-cover types on a global scale. It also aims to examine the dynamics of the products in monthly timescale and find their relationships with surface properties such as soil moisture and vegetation change both spatially and temporally.

\section{Data sets}

Five years (from January 2003 to December 2007) of land emissivity data from different providers were collected. The sensors included in this study are AMSR-E, SSM/I, TMI, and WindSat. The SSM/I-based emissivity product is generated by Centre National de la Recherche Scientifique (CNRS) in France (Prigent et al., 1998, 2006). This data set has the longest available record of emissivity estimates for frequencies of 19 to $85 \mathrm{GHz}$. The data set uses International Satellite Cloud Climatology Project (ISCCP) skin temperature and the NCEP reanalysis for air temperature and water vapor column.

The AMSR-E instantaneous emissivity has been produced by the National Oceanic Atmospheric Administration (NOAA) Cooperative Remote Sensing and Technology (CREST) center for more than 6 years and is available on a monthly scale on the National Snow and Ice Data Center (NSIDC) website (Norouzi, 2013). This retrieval uses ancillary data from ISCCP and the TIROS Operational Vertical Sounder (TOVS) for skin temperature, cloud mask, and atmospheric information (Rossow and Schiffer, 1999).

The emissivity product based on TMI observations is provided by Nagoya University in monthly format (Furuzawa et al., 2012). This product uses Japanese 25 -year ReAnalysis (JRA-25) as ancillary data (Onogi et al., 2007). It finds required parameters from JRA- 25 by an interpolation technique based on TMI acquisition time for each pixel.

WindSat emissivity estimates are derived using ancillary data from Atmospheric Infrared Sounder (AIRS) and NCEP data. Further details about the retrieval algorithms and the product can be obtained from Turk et al. (2014).

All sensors, except TMI, are sun-synchronous and have ascending and descending overpasses. They are all microwave imagers (not sounders) and have a few years of overlap in their life span. There are some differences in frequencies, in- cidence angle, acquisition time, footprint, and calibration of these microwave sensors. Unlike other polar orbiting sensors that are considered in this study, the geographic coverage of TMI does not include areas above and below $38^{\circ} \mathrm{N}$ and $38^{\circ} \mathrm{S}$ latitude, respectively. The details of these differences are listed in Table 1.

A vegetation and land use global data set compiled from a large number of published sources at $1^{\circ}$ equal area grid resolution by Matthews (1983), adopted by Prigent et al. (2001) in $0.25^{\circ}$, is used in this study to distinguish among various surface types. The land classes include rain forest, evergreen forest, deciduous forest, evergreen woodland, deciduous woodland, cultivation, grassland, tundra, shrubland, and desert.

\section{Method}

Resampling of data products: first, it was necessary to reprocess the selected land emissivity products by reprojecting them in a common equal-area grid $\left(0.25^{\circ}\right.$ at the Equator $)$ projection and resampling them to the same spatial resolution. This step is required to make the intercomparison possible despite the systematic differences that it may introduce. There were no further adjustments done, in terms of interfrequency or interangle interpolations, to account for the differences in the sensors' configurations and observation geometries. The intercomparison was performed on a global scale except in the case of TMI, where the spatial coverage of the sensor was limited to the $\pm 38^{\circ}$ latitude region.

The mean values of monthly emissivity products from each sensor were calculated for the period of 2003 to 2007 to determine the relative differences among the monthly variation of emissivity products.

Moreover, the standard deviation of monthly estimates from each product for each pixel is calculated as indicator of dynamics of emissivity using 5 years of monthly data.

Emissivity microwave polarization difference index (MPDI): the intercomparison of different land emissivity products included analysis of their sensitivity to the different land surface parameters. To this end, a polarization index, the emissivity microwave polarization difference index (MPDI), was calculated. The MPDI should exhibit greater sensitivity to surface parameters and should mitigate the effect of the atmosphere and land surface temperature and therefore reduce their impact on the reliability of the products' intercomparison. In addition, it has been shown that differences between horizontal and vertical polarization signals contain a wealth of information regarding soil moisture and vegetation density (Felde, 1998). Among the indices that accounted for the polarization difference, the microwave polarization difference index for brightness 
temperature was largely used. The emissivity-based MPDI is defined as

$\mathrm{MPDI}=\frac{\varepsilon_{\mathrm{v}}-\varepsilon_{\mathrm{h}}}{\varepsilon_{\mathrm{v}}+\varepsilon_{\mathrm{h}}}$,

where $\varepsilon_{\mathrm{V}}$ and $\varepsilon_{\mathrm{h}}$ are emissivities at vertical and horizontal polarization, respectively, for a specific frequency. This index is calculated for each pixel and then is evaluated with satellitebased soil moisture and the normalized difference vegetation index (NDVI).

\section{Results and discussion}

Monthly mean values were calculated for all products from January 2003 to December 2007. The obtained results were averaged over the different land-cover types, namely, rain forest, evergreen woodland, grassland, and deserts. Figure 1 reveals clear differences among the emissivity products which are sensitive to frequencies and land-cover conditions. Over densely vegetated areas such as rain forests the discrepancies among the products are larger at high frequencies to reach, for instance, 0.06 between AMSR-E $89 \mathrm{GHz}$ and TMI $85 \mathrm{GHz}$ horizontal emissivity values. The products show better agreement at lower frequencies which involve less scattering and deeper penetration into the canopy unlike highfrequency brightness temperature which penetrates less and reflects the top of the canopy microwave radiating temperature. The use of the canopy skin temperature, in the rain forest region, to approximate the canopy effective temperature for low and high frequencies in the emissivity retrieval can lead to discrepancies among the products that are frequency dependent (Norouzi et al., 2011; Prigent et al., 1999). The effective optical depth of the canopy depends on the vegetation water content, intercepted water in rain forests, and the vegetation structure and type. Moreover, the differences can be attributed to the divergences among the products when accounting for the atmospheric perturbations which are considerable in the high range of frequencies due to the higher water vapor effect in tropical and rain forest regions.

In desert, unlike rain forest regions, maximum differences are at lower frequencies and agreements relatively improve at higher frequencies, particularly in the horizontal polarization values. The deeper penetration of the microwave signal especially at low frequencies in desert which leads to differences in the diurnal amplitude and phase of skin temperature and microwave brightness temperature can introduce considerable error in emissivity retrievals (Norouzi et al., 2012). This issue is more highlighted in desert areas due to moisture scarcity and minimal vegetation interferences. These results are consistent with a previous study by Tian et al. (2014) in terms of systematic differences at various frequencies. Also, a wider gap can be noticed between the average monthly emissivity values in the horizontal and vertical polarizations over desert. The horizontal polarization increase with increasing frequencies while the vertical polarization declines with the frequency increase (Yubao et al., 2014). This behavior was consistent among all investigated products.

According to Fig. 1, AMSR-E has the highest variation of emissivity spectrally. AMSR-E has lower emissivities for 10,19 , and $37 \mathrm{GHz}$, and higher at $89 \mathrm{GHz}$. At $89 \mathrm{GHz}$, the microwave signal is more affected by the atmosphere and the impact of the differences in ancillary data and radiative transfer modeling can be critical. It was noticed that both horizontal and vertical polarizations reflect the same variability in terms of differences with other sensors (solid and dashed lines). However, the differences between horizontal and vertical polarization emissivity values increase as vegetation density decreases from rain forests to desert land cover.

Previous studies have shown that differences in channel frequencies and incidence angles between AMSR-E and SSMI/I channels may lead to around 0.01 error in the emissivity retrieval (Norouzi et al., 2011). TMI and SSM/I have similar emissivity values especially at 10,19 , and $37 \mathrm{GHz}$. The discrepancies are noticeable in $89 \mathrm{GHz}$. SSM/I and TMI emissivities are more stable with varying frequency. The emissivities from AMSR-E and WindSat are less consistent than other products almost at all frequencies and land-cover types. The results for other land-cover types are the same as the presented ones.

The seasonality of the different land emissivity products was analyzed. Standard deviations of monthly land emissivity estimates for 5 years of data at different frequencies were calculated (Fig. 2). Higher variation is observed across all products (higher standard deviation) in monthly estimates over areas where surface properties such as moisture and vegetation change more significantly over the seasons due to the presence/melting of snow during winter/summer, vegetation growth, and seasonal precipitation. Figure 2 depicts the calculated standard deviations of monthly emissivity means at $37 \mathrm{GHz}$ (horizontal polarization) for all sensors. SSM/I and AMSR-E emissivity values show high standard deviations greater than $4 \%$ (dark red) in high-latitude and boreal regions, which do not seem to be present in the WindSat values in the horizontal polarization. The highest standard variation for WindSat at northern latitudes was less than 0.03 . Das et al. (2014) reported a higher disagreement between AMSR-E and WindSat brightness temperatures in Dom-C area in Antarctica in horizontal polarization. The relatively high standard deviation values across all sensors could be explained by the transition between freeze and thaw conditions throughout the seasons. However, one should expect consistency between AMSR-E and WindSat because of their similar configurations. In line with what was stated in Das et al. (2014), the difference in incident angles $\left(49.9^{\circ}\right.$ for WindSat and $55^{\circ}$ for AMSR-E) seems to have a considerable impact on the northern latitude retrieval, affecting more the horizontal polarization observation than the vertical polarization ones. Moreover, the snow-covered regions are also flagged 
Table 1. List of global land surface emissivity products used in this study.

\begin{tabular}{lllll}
\hline Sensor & Provider & \multicolumn{1}{c}{ Frequencies } & Incidence angle & Ancillary data \\
\hline AMSR-E & NOAA-CREST & $6.9,10.65,18.7,23.8,36.5$, and 89.0 & 550 & ISCCP-DX, TOVS \\
SSM/I & CNRS-France & $19.35,22.235(\mathrm{v}), 37.0$, and 85.5 & 530 & ISCCP-DX, NCEP Reanalysis \\
TMI & Nagoya Uni. & $10.65,19.35,21.3(\mathrm{v}), 37.0$, and 85.5 & 53.40 & JRA-25 \\
WindSat & JPL/NRL & $6.8,10.7,18.7,23.8$, and 37.0 & 49.90 to 55.30 & NCEP Reanalysis, AIRS \\
\hline
\end{tabular}

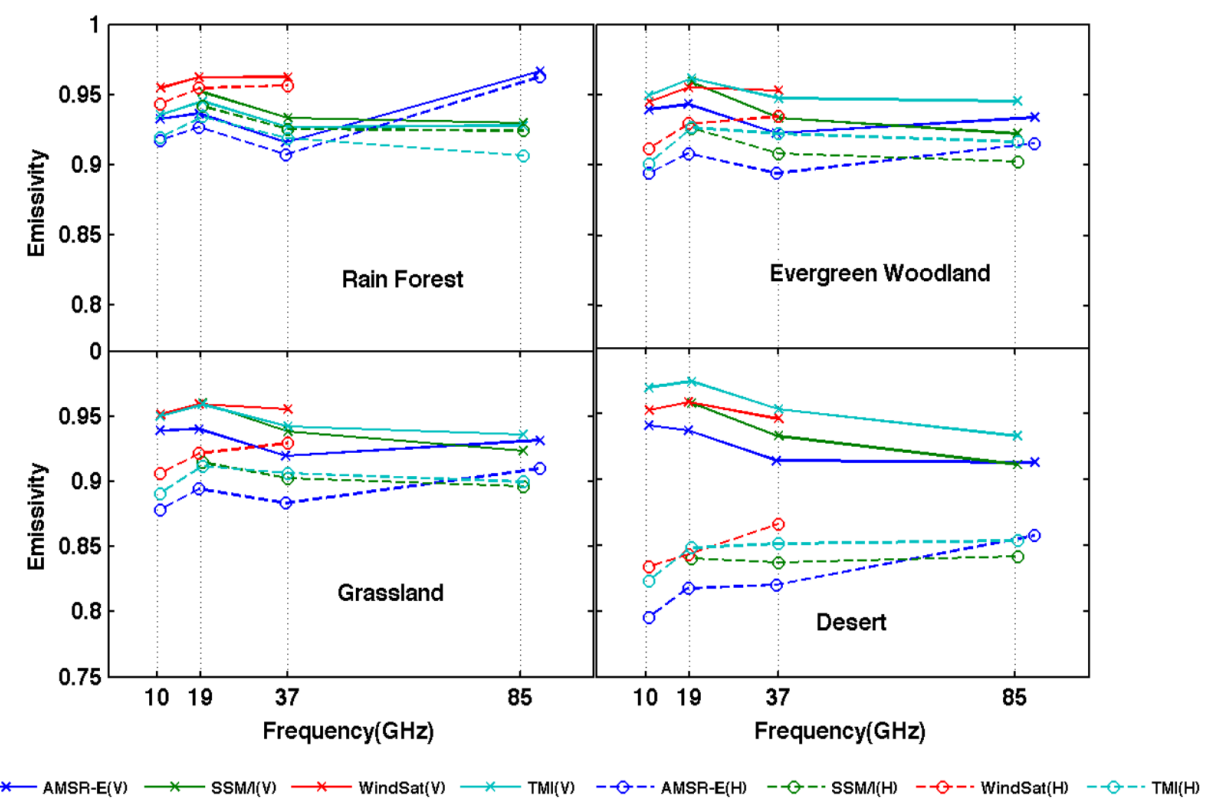

Figure 1. Mean of monthly emissivity values (from 2003 to 2007) for rain forest, evergreen woodland, grassland, and desert regions on a global scale from AMSR-E, TMI, SSM/I, and WindSat. The solid lines present vertical polarization, and dashed lines are for horizontal polarization.

in the retrieval of WindSat emissivities which caused lower variability in the Northern Hemisphere (Turk et al., 2014).

Other land-cover signatures are also seen in monthly standard deviations. For instance, WindSat clearly shows a low emissivity standard deviation (less than $0.005 \%$ ) over the Amazon and Congo with persistent and steady dense vegetation. The Sahara is clearly distinguishable from SSM/I emissivity values when low emissivity values contrast with the transition region (south of the Sahara) with higher emissivity variation because of seasonal variation of moisture and vegetation cover. Surface properties in terms of soil moisture do not change in the Sahara with almost no vegetation cover. This can explain the low emissivity change and standard deviation. AMSR-E and TMI also show the same pattern, but it is less recognizable in the WindSat map. There are small regions that show a very high standard deviation in South America, corresponding to floodplains that are seasonally inundated, which explains the high standard deviation values in all products except WindSat. Moreover, the standard deviation of the TMI emissivity values in the Amazon seems to be higher (around 0.01-0.015) than the values obtained with the other sensors (around 0.005-0.01). In WindSat, owing to the simplified parameterizations of the vegetation in the retrieval, the variability of emissivity is not very high in transition areas (Turk et al., 2014). Similar results of standard variation analysis also were found in other channels that are not presented here. Overall, despite the relative differences in standard deviation values, the dynamics of emissivity products tend to be related to known changes in surface condition across the globe.

The relationship between the investigated products and two key surface parameters, namely, soil moisture and vegetation cover, was assessed. The emissivity MPDI values are plotted against soil moisture content and NDVI values over the TMI coverage region for all products (Fig. 3). Soil moisture estimates are microwave-based from WindSat C-band observations because of its availability over the time period of this study (Turk et al., 2014). NDVI estimates are from MODIS and are available every 16 days globally. Monthly averages of NDVI and soil moisture estimates are calculated in this study. Emissivity-based MPDI values for the range of soil moisture and NDVI values at $19 \mathrm{GHz}$ are shown in Fig. 3 


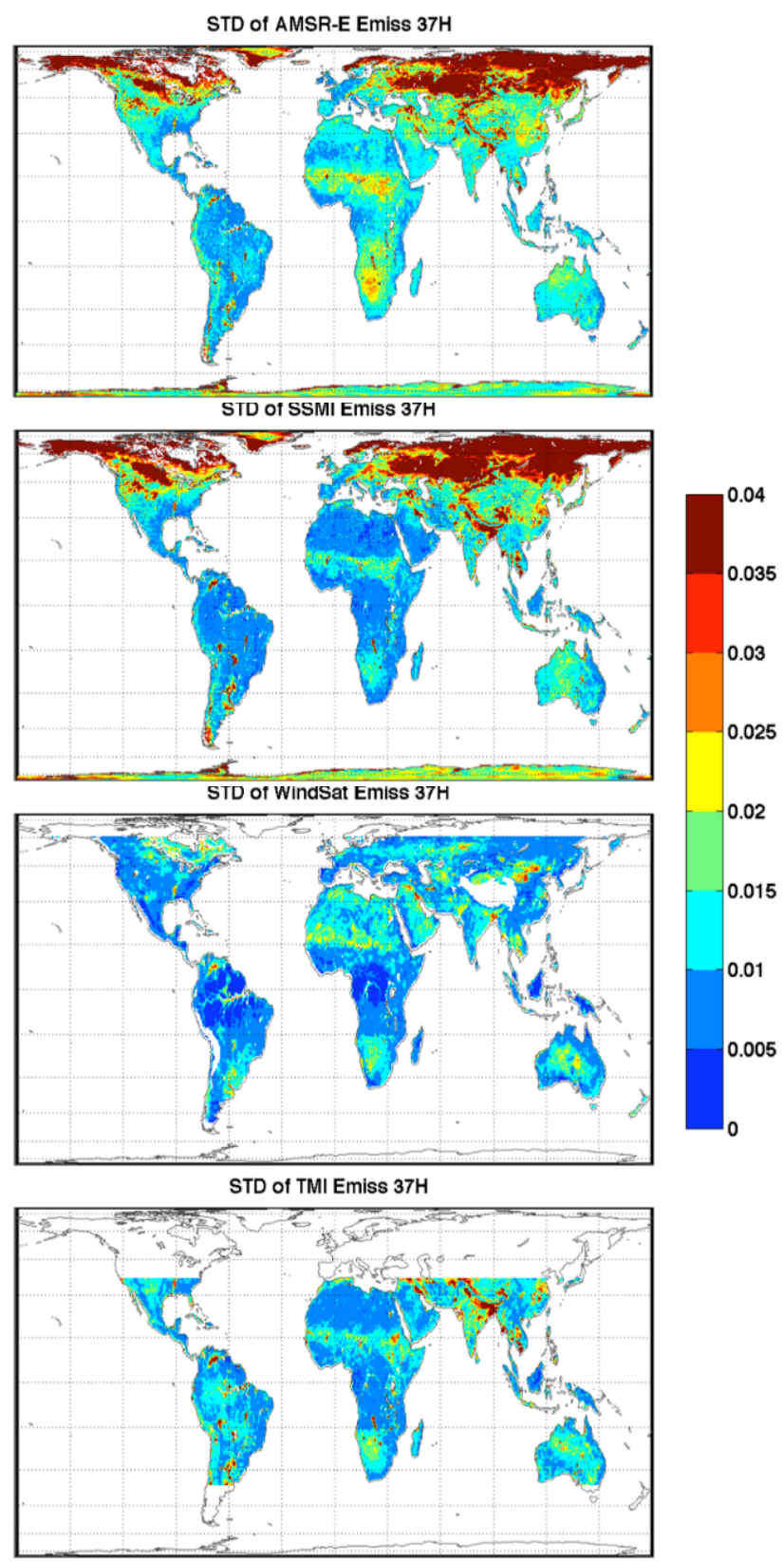

Figure 2. Monthly standard deviation of emissivity estimates from AMSR-E, SSM/I, WindSat, and TMI from 2003 to 2007 at $37 \mathrm{GHz}$ (horizontal polarization).

for all products for July 2003. High emissivity-based MPDI values greater than 0.06 are found for low soil moisture and low NDVI values in all products. This is in line with previous studies that suggest that the contrast between horizontal and vertical microwave signals is higher in desert regions with almost no vegetation (e.g., Norouzi et al., 2011; Prigent et al., 2006). Soil moisture has been found to decrease the emissivity across the frequencies (Basist et al., 1998). Lower emissivity-based MPDI values are seen as vegetation density and soil moisture increase in all products. Higher vegetation
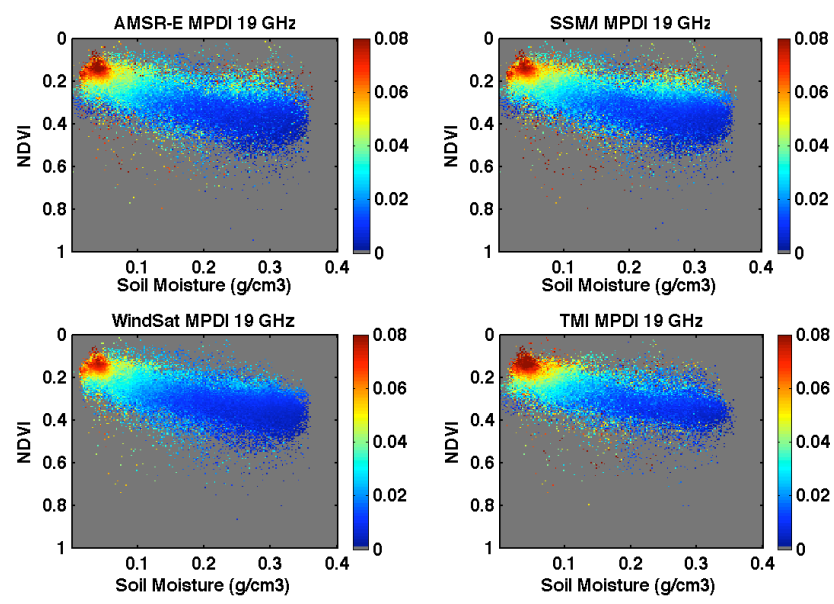

Figure 3. Emissivity MPDI values from various sensors/providers at different NDVI and soil moisture ranges at $19 \mathrm{GHz}$ for July 2003.

causes more scattering of microwave signal, and therefore the difference between horizontal and vertical polarizations decreases. The pattern is very similar for all products except WindSat, which shows lower values (about 0.05) in the low soil moisture range. This could be because the soil moisture data are based on WindSat observations. Consequently, one can conclude that emissivity retrievals are consistent in terms of their relationship between emissivity-based MPDI and surface condition.

The comparison of emissivity and NDVI as indicators of vegetation density and surface condition revealed that the differences between horizontal and vertical emissivity values $\left(e_{\mathrm{H}}-e_{\mathrm{V}}\right)$ have positive correlation with vegetation and soil moisture values (Norouzi et al., 2011; Prigent et al., 2006) using AMSR-E and SSM/I values. Monthly temporal correlation between $e_{\mathrm{H}}-e_{\mathrm{V}}$ and NDVI values were calculated for 5 years globally for each pixel. The calculated correlation values for all products at $19 \mathrm{GHz}$ are shown in Fig. 4. At first glance, all products present a high correlation (more than 0.9 ) with monthly NDVI variations in most regions. This shows that emissivity estimates in these regions are in phase with what is expected from the surface in terms of vegetation. However, desert regions in the Sahara, Australia, and the Middle East as well as regions with very high vegetation density show a much lower correlation (around -0.2 to 0 ). This is because in desert regions there is almost no vegetation and the surface vegetation and soil moisture do not change. Besides, in highly vegetated areas such as the Amazon and Congo, the vegetation density remains high throughout the year. Therefore, the NDVI and $e_{\mathrm{H}}-e_{\mathrm{V}}$ variation comparisons are not representative of the surface condition variation in highly vegetated and desert areas. The observed variability could be because of noises or atmospheric residuals in the emissivity retrievals. WindSat has a different spatial pattern, especially in the semi-arid region that marks the transition zone between desert and rain forest regions in Africa. 
One key factor in emissivity retrievals is the cloud mask information that is utilized to mask out the cloudy scenes and to ensure that the retrieval of emissivity is only performed over cloud-free pixels. The investigated data products do not necessarily use the same cloud mask. The inconsistency among the detected cloudy pixels in the analyzed products could be an additional source of discrepancy, which can also explain the differences in the mean monthly maps. The differences between emissivities could be up to $10 \%$ at higher frequencies with false detection of cloudy scenes.

NWP models rely on radiative transfer (RT) models (e.g., Community Radiative Transfer Model (CRTM)) that are used to determine the state of the atmosphere and account for the radiative transfer in different spectral ranges, such as, among others, the microwave frequencies (window and sounding channels). Estimates of land surface emissivity are particularly important as NWP models attempt to assimilate passive microwave observations over land (Prigent et al., 2006). Specifically, when it comes to window channels, the surface radiance that is controlled by the land emissivity should be determined. The simulations using the RT models should be carried across a wide range of angles and frequencies. Sensors can only provide estimates at specific angles and frequencies.

The results of this study can serve the development of a global blended land emissivity product that accounts for the identified spatial inconsistencies among the different existing land emissivity products. A blended product may balance the errors among the distinct products as such product could be obtained using a weighted regression among all emissivity retrievals where weights should vary spatially to account for the spatial variability of the consistency among the products (Sahoo et al., 2011). Given the instantaneous scale of NWP models, the assimilation of such blended product may not be possible. However, such a product could be useful if it considered with an error estimate that accounts for the instantaneous bias. Using forward operators in assimilation models, some instantaneous biases may be removed by additional observations such as infrared sounders and radiosondes measurements. This should lead to weather forecasts that are more accurate than obtained when any individual land emissivity product is used. The emissivity blended composite could also satisfy the needs of many precipitation retrieval algorithms (Skofronick-Jackson et al., 2013). Moreover, land emissivity is sensitive to soil wetness, which can affect brightness temperatures when they are used in NWP models. The perturbations in emissivity due to the soil moisture effect may propagate significant error in atmospheric information estimates from when they are not accounted for. This could be particularly important since the sensors have different acquisition times which may reflect some variability in their estimates of soil moisture (especially AMSR-E with 01:30/13:30 crossing times) (Jackson et al., 1997). This variability may have imposed some discrepancies among sensors, although they are aggregated to a monthly scale. A cross
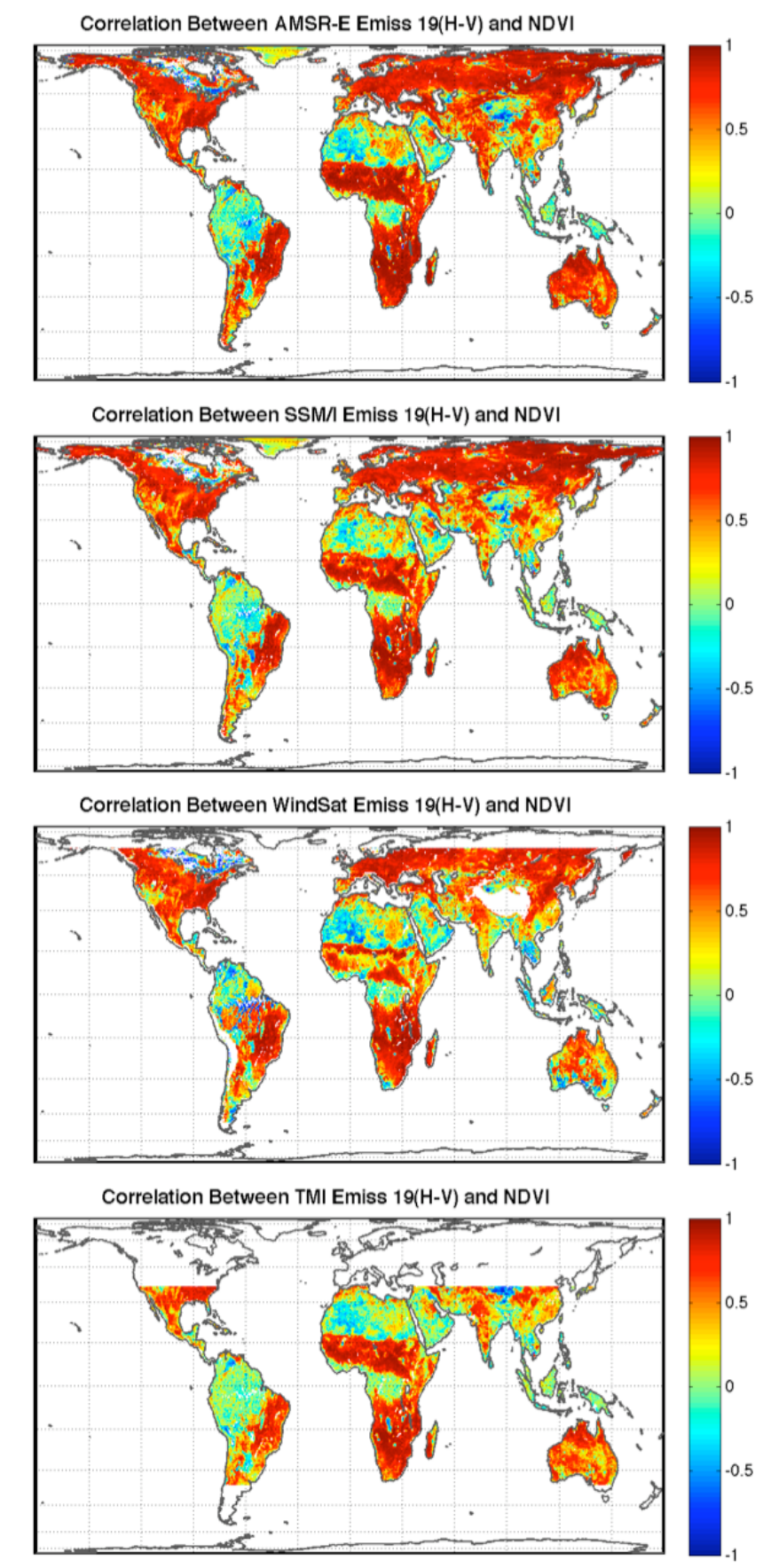

Figure 4. Correlation maps between temporal variations of $e_{\mathrm{H}}-e_{\mathrm{V}}$ from all sensors at $19 \mathrm{GHz}$ with monthly NDVI values from 2003 to 2007 .

calibration that involves data from all the sensors used in this study is necessary to detect the magnitude of the discrepancies in the raw data and the determined brightness temperatures and to apply appropriate corrections to mitigate its impact on land emissivity retrievals. The efforts part of the Global Precipitation Measurement mission showed small differences between similar channels (but not identi- 
cal) of conical orbiting radiometers on two pairs of sensors, TMI/WindSat and TMI/AMSR-E. However, in some other channels, such as $37 \mathrm{~V}$, the differences between TMI and WindSat could reach $3 \mathrm{~K}$ (Wilheit, 2013), which can have a non-negligible influence on emissivity estimates. This difference causes about 0.01 difference in emissivity estimates, which is significant especially in regions where emissivity values are higher than 0.95 (Norouzi et al., 2012).

\section{Conclusions}

The global emissivity retrieval products from various passive microwave sensors over land were intercompared on a monthly scale for a 5-year period of time. The sensors have a general configuration difference that can induce some systematic differences among them. Previous studies have shown that differences due to channel frequency and incidence angle are not significant especially at lower frequencies. Systematic differences among retrievals could be due to ancillary data and the radiative transfer models used. All products use a relatively similar retrieval algorithm to estimate emissivity on top of the canopy or the land surface. However, the differences in ancillary data and the ways they may be interpolated or resampled prior to their use in the retrieval may affect the obtained emissivity values. In addition, the differences among the methods to account for atmospheric contributions are among the sources of differences.

Emissivity values are the signals from microwave observation after removing the effect of temperature and atmosphere from the brightness temperature. The differences at lower frequencies were found to be higher in desert regions because of penetration depth and discrepancies between skin temperature and microwave brightness temperature originating depths. At higher frequencies (more than $37 \mathrm{GHz}$ ) due to atmospheric residuals in emissivity values, the inconsistencies increase in regions with high vegetation density and water vapor amount. Systematic uncertainties are similar between horizontal and vertical polarizations. The emissivity values from SSM/I and TMI were found to be more consistent over different land-cover types. The maximum systematic difference among emissivities was found to be about $4 \%$ at all frequencies and polarizations. This could be an indicator of uncertainty level from emissivity retrievals despite $10 \%$ error in physical model-based emissivities (Ringerud et al., 2014).

The seasonal variation of emissivities was evaluated by looking at monthly standard deviation values, and they were found to be consistent with what is expected qualitatively from the surface in most regions except the Amazon and South America. Moreover, the dynamics of the emissivity estimates compared to surface properties such as soil moisture and vegetation were found to be more promising than the absolute value estimates.
Results of this study highlight the need for a more thorough review of emissivity values before using them in physical models or precipitation measurement algorithms. Daily or instantaneous emissivity estimates from different sources may also yield more information about systematic and random uncertainties from retrievals. For more in-depth error analysis and to find the sources of discrepancies, an analysis can be done by applying the same inputs for different algorithms that were used for all four sensors. Moreover, modifications could be applied to each retrieval method to account for instantaneous biases that could be estimated with respect to a blended composite emissivity product.

Acknowledgements. This publication was made possible by NOAA, Office of Education Educational Partnership Program award NA11SEC4810004. Its contents are solely the responsibility of the award recipient and do not necessarily represent the official views of the US Department of Commerce, NOAA.

Edited by: J. Munchak

\section{References}

Basist, A., Grody, N. C., Peterson, T. C., and Williams, C. N.: Using the Special Sensor Microwave/Imager to Monitor Land Surface Temperatures, Wetness, and Snow Cover, J. Appl. Meteorol., 37, 888-911, doi:10.1175/15200450(1998)037<0888:utssmi>2.0.co;2, 1998.

Boukabara, S.-A., Garrett, K., Chen, W., Iturbide-Sanchez, F., Grassotti, C., Kongoli, C., Chen, R., Liu, Q., Yan, B., Weng, F., Ferraro, R., Kleespies, T. J., and Meng, H.: MiRS: An All-Weather 1DVAR Satellite Data Assimilation and Retrieval System, IEEE T. Geosci. Remote, 49, 3249-3272, doi:10.1109/tgrs.2011.2158438, 2011.

Das, N. N., Colliander, A., Chan, S. K., Njoku, E. G., and Li, L.: Intercomparisons of Brightness Temperature Observations Over Land From AMSR-E and WindSat, IEEE T. Geosci. Remote, 52, 452-464, doi:10.1109/tgrs.2013.2241445, 2014.

Felde, G. W.: The effect of soil moisture on the $37 \mathrm{GHz}$ microwave polarization difference index (MPDI), International J. Remote Sens., 19, 1055-1078, doi:10.1080/014311698215603, 1998.

Ferraro, R. R., Peters-Lidard, C. D., Hernandez, C., Turk, F. J., Aires, F., Prigent, C., Xin, L., Boukabara, S., Furuzawa, F. A., Gopalan, K., Harrison, K. W., Karbou, F., Li, L., Chuntao, L., Masunaga, H., Moy, L., Ringerud, S., Skofronick-Jackson, G. M., Yudong, T., and Nai-Yu, W.: An Evaluation of Microwave Land Surface Emissivities Over the Continental United States to Benefit GPM-Era Precipitation Algorithms, IEEE T. Geosci. Remote, 51, 378-398, doi:10.1109/tgrs.2012.2199121, 2013.

Furuzawa, F. A., Masunaga, H., and Nakamura, K.: Development of a land surface emissivity algorithm for use by microwave rain retrieval algorithms, 85231W-85231W-85212,Proc. SPIE 8523, Remote Sensing of the Atmosphere, Clouds, and Precipitation IV, 8523, W1-12, doi:10.1117/12.977237, 2012.

Jackson, T. J., Oneill, P. E., and Swift, C. T.: Passive microwave observation of diurnal surface soil moisture, IEEE T. Geosci. Remote, 35, 1210-1222, doi:10.1109/36.628788, 1997. 
Karbou, F., Prigent, C., Eymard, L., and Pardo, J. R.: Microwave land emissivity calculations using AMSU measurements, IEEE T. Geosci. Remote, 43, 948-959, doi:10.1109/tgrs.2004.837503, 2005.

Karbou, F., Gerard, E., and Rabier, F.: Microwave land emissivity and skin temperature for AMSU-A and -B assimilation over land, Q.y J. Roy. Meteor. Soc., 132, 2333-2355, doi:10.1256/qj.05.216, 2006.

Matthews, E.: Global Vegetation and Land-Use Data-Bases For Climate Studies, B. Am. Meteorol. Soc., 64, 793-794, 1983.

Moncet, J., Liang, P., Galantowicz, A., Lipton, A., Uymin, G., Prigent, C., and Grassotti, C.: Land Surface Microwave Emissivities Derived from AMSR-E and MODIS Measurements with Advanced Quality Control, J. Geophys. Res.-Atmos., 116, D16104, doi:10.1029/2010JD015429, 2011.

Norouzi, H., Temimi, M., Rossow, W. B., Pearl, C., Azarderakhsh, M., and Khanbilvardi, R.: The sensitivity of land emissivity estimates from AMSR-E at $\mathrm{C}$ and $\mathrm{X}$ bands to surface properties, Hydrol. Earth Syst. Sci., 15, 3577-3589, doi:10.5194/hess-153577-2011, 2011.

Norouzi, H., Rossow, W., Temimi, M., Prigent, C., Azarderakhsh, M., Boukabara, S., and Khanbilvardi, R.: Using microwave brightness temperature diurnal cycle to improve emissivity retrievals over land, Remote Sens. Environ., 123, 470-482, doi:10.1016/J.Rse.2012.04.015, 2012.

Norouzi, H.,Temimi, M., Rossow, W. B., and Khanbilvardi, R.: AMSR-E/Aqua Monthly Global Microwave Land Surface Emissivity, Boulder, Colorado USA: NASA National Snow and Ice Data Center Distributed Active Archive Center, avaialbale at: http://nsidc.org/data/nsidc-0543 last access: 9 March 2015, 2013.

Onogi, K., Tsutsui, J., Koide, H., Sakamoto, M., Kobayashi, S., Hatsushika, H., Matsumoto, T., Yamazaki, N., Kamahori, H., Takahashi, K., Kadokura, S., Wada, K., Kato, K., Oyama, R., Ose, T., Mannoji, N., and Taira, R.: The JRA-25 Reanalysis, J. Meteorol. Soc. Jpn., 85, 369-432, 2007.

Prigent, C., Rossow, W. B., and Matthews, E.: Global maps of microwave land surface emissivities: Potential for land surface characterization, Radio Sci., 33, 745-751, 1998.

Prigent, C., Rossow, W. B., Matthews, E., and Marticorena, B.: Microwave radiometric signatures of different surface types in deserts, J. Geophys. Res.-Atmos., 104, 12147-12158, 1999.
Prigent, C., Aires, F., Rossow, W., and Matthews, E.: Joint characterization of vegetation by satellite observations from visible to microwave wavelengths: A sensitivity analysis, J. Geophys. Res.-Atmos., 106, 20665-20685, 2001.

Prigent, C., Aires, F., and Rossow, W. B.: Land surface microwave emissivities over the globe for a decade, B. Am. Meteorol. Soc., 87, 1573-1584, doi:10.1175/bams-87-11-1573, 2006.

Ringerud, S., Kummerow, C., Peters-Lidard, C., Tian, Y., and Harrison, K.: A Comparison of Microwave Window Channel Retrieved and Forward-Modeled Emissivities Over the U.S. Southern Great Plains, IEEE T. Geosci. Remote, 52, 2395-2412, doi:10.1109/tgrs.2013.2260759, 2014.

Rossow, W. B., and Schiffer, R. A.: Advances in understanding clouds from ISCCP, B. Am. Meteorol. Soc., 80, 2261-2287, 1999.

Sahoo, A., Pan, M., Troy, T., Vinukollu, R., Sheffield, J., and Wood, E.: Reconciling the global terrestrial water budget using satellite remote sensing, Remote Sens. Environ., 115, 1850-1865, doi:10.1016/j.rse.2011.03.009, 2011.

Skofronick-Jackson, G. M., Johnson, B. T., and Munchak, S. J.: Detection Thresholds of Falling Snow From Satellite-Borne Active and Passive Sensors, IEEE T. Geosci. Remote, 51, 4177-4189, doi:10.1109/tgrs.2012.2227763, 2013.

Tian, Y., Peters-Lidard, C. D., Harrison, K. W., Prigent, C., Norouzi, H., Aires, F., Boukabara, S. A., Furuzawa, F. A., and Masunaga, H.: Quantifying Uncertainties in Land-Surface Microwave Emissivity Retrievals, IEEE T. Geosci. Remote, 2, 829840, doi:10.1109/tgrs.2013.2244214, 2014.

Turk, F. J., Li, L., and Haddad, Z. S.: A Physically Based Soil Moisture and Microwave Emissivity Data Set for Global Precipitation Measurement (GPM) Applications, IEEE T. Geosci. Remote, 52, 7637-7650, doi:10.1109/tgrs.2014.2315809, 2014.

Weng, F. Z., Yan, B. H., and Grody, N. C.: A microwave land emissivity model, J. Geophys. Res.-Atmos, 106, 20115-20123, 2001.

Wilheit, T. T.: Comparing Calibrations of Similar Conically Scanning Window-Channel Microwave Radiometers, IEEE T. Geosci. Remote, 51, 1453-1464, doi:10.1109/tgrs.2012.2207122, 2013.

Yubao, Q., Lijuan, S., and Wenbo, W.: Study of the microwave emissivity characteristics over Gobi Desert, Earth Environ. Sci., 17, 012249, doi:10.1088/1755-1315/17/1/012249, 2014. 